\title{
Non-Surgical Management of Mandibular First Premolar with Two Roots:
} Case Report

\author{
AboalSamh Duaa, BDS, MSc, Cert Endo, SBARD*
}

\begin{tabular}{|c|c|}
\hline $\begin{array}{l}\text { Dental Center, prince Sultan Military Medical City (PSMMC), } \\
\text { Riyadh, KSA, Saudi Arabia. }\end{array}$ & $\begin{array}{l}{ }^{*} \text { Correspondence: } \\
\text { AboalSamh Duaa, Dental Center, prince Sultan Military Medical } \\
\text { City (PSMMC), Riyadh, KSA, Saudi Arabia, Tel: 00966505464675, } \\
\text { E-mail: Duaa1_2000@yahoo.com. }\end{array}$ \\
\hline & Received: 02 June 2018; Accepted: 24 June 2018 \\
\hline
\end{tabular}

Citation: AboalSamh Duaa. Non-Surgical Management of Mandibular First Premolar with Two Roots: Case Report. Oral Health Dental Sci. $2018 ; 2(2) ; 1-3$.

\section{ABSTRACT}

Knowledge of basic root and root canal morphology and possible variation in anatomy of root canal system is important to achieve successful non-surgical root canal treatment this is followed by negotiation, cleaning and shaping and obturation of the entire canal system in three dimensions. This case presents the diagnosis and successful non-surgical endodontic management of a two rooted mandibular first premolar.

Keywords

Mandibular first premolars, Root canal morphology, Root canal therapy.

\section{Introduction}

Mandibular premolars have been stated to be the most difficult to treat as they have a high flare-up and failure rate therefor they are challenging teeth to be treated endodontically, especially when they present with multiple roots or canals.

Mandibular first premolar usually has a single root and a single canal and is typically described in literature as single rooted tooth. Two rooted, three rooted and four rooted variations have also been reported, but are rare [1].

This article describes the successful clinical management of a mandibular first premolar with two roots.

\section{Case Report}

A 40-year old Saudi female patient with a noncontributory medical history reported to our endodontic department with a chief complaint of pain in the lower left back tooth since one month. Upon intraoral clinical examination, there was a big temporary felling on the lower left first premolar tooth \#34.

The tooth was not sensitive to cold testing, no swelling or sinus tract but sensitive to vertical percussion.
Radiographic evaluation of the involved tooth was taken with straight angulation (Figure 1A), and a second radiograph with a more mesial angulation reveled unusual anatomy of two roots (Figure 1B). There was also widening of the apical periodontium, indicating periapical pathology and necessity for root canal treatment.
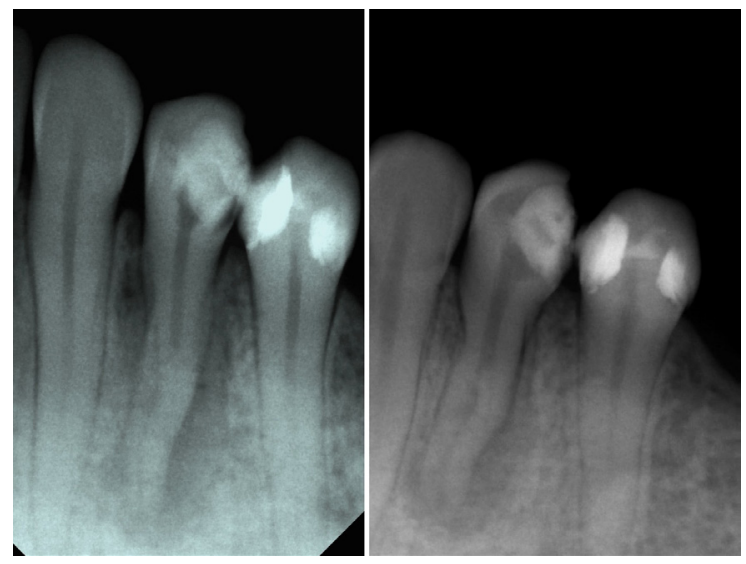

Figure 1A: Tooth \#34 (Straight angulation) radiograph showing Canal suddenly stops on the radicular region on radiograph.

Figure 1B: Tooth \#34 (mesial angulation) radiograph showing extra root and canal. The second canal exists around mid-root.

After clinical and radio graphical examination tooth \#34 was diagnosed with acute apical periodontitis and endodontic therapy was decided. 
The tooth was anesthetized by inferior alveolar nerve block using $2 \%$ solution of lignocaine hydrochloride containing 1:80000 adrenalines (Lignox 2\% A, Warren, Indoco). After the tooth was isolated with rubber dam, endodontic access cavity was prepared with a round diamond bur in a high speed airotor hand piece. To gain sufficient access to the canals, the conventional access opening was modified into one that was wider bucco-lingually as the roots were bucco-lingually oriented. The orifice location was not easy as the coronal pulp chamber was long and the separation of the roots was from the middle third of the roots.

After careful inspection with the aid of magnifying loupe (seiler loupes) and a sharp DG 16 explorer, the canal orifices were located. Gates- Glidden drills \# 4, 3, 2 with a brushing motion, in a crown down fashion was used to enlarge the orifices to achieve a straight line access to the apex. After obtaining the canal patency, a no \#10 $\mathrm{K}$ file (DENTSPLY, Mollifier) was pre-curved and inserted into each of the canals, and then the working length radiograph was taken and measured (Figure 2).

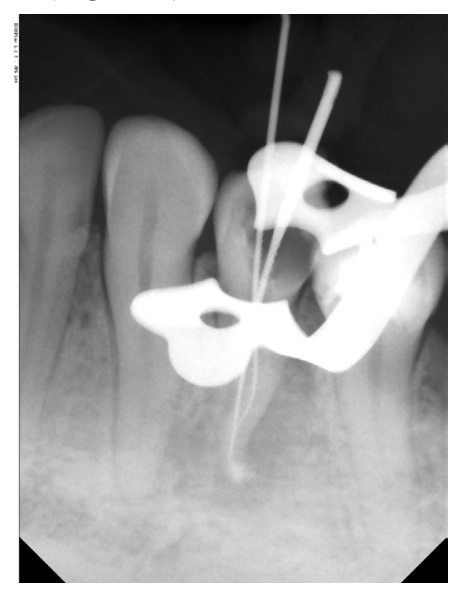

Figure 2: Working length radiograph for both canals.

The two canals were then cleaned and shaped with hand $\mathrm{k}$ file and then with nickel titanium rotary files (easy Race, Sybron Endo, Orange, California, USA) up to size 250.04 tapered. Calcium hydroxide paste was placed in both canals as an intracanal medicament and the tooth sealed with IRM (caulk/DENTSPLY Milford, Delaware, USA) (Figure 3).

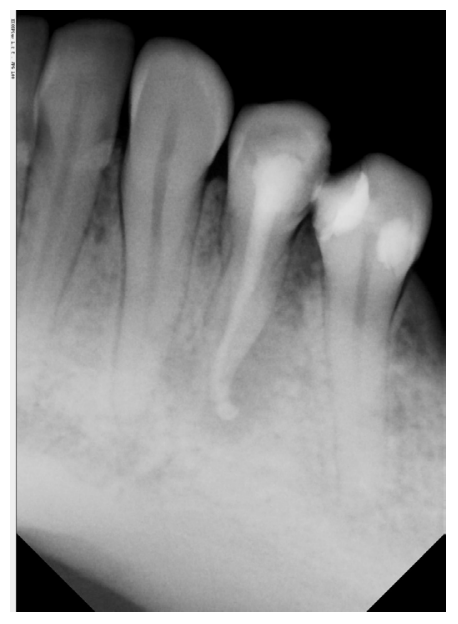

Figure 3: Canals filled with (calcium hydroxide) intra canal medicament.

After one week the tooth was asymptomatic and both canals were recapitulated. A radiograph with master apical file taken (Figure 4 ), then canals were irrigated, dried and another radiograph taken with master cone (Figure 5).

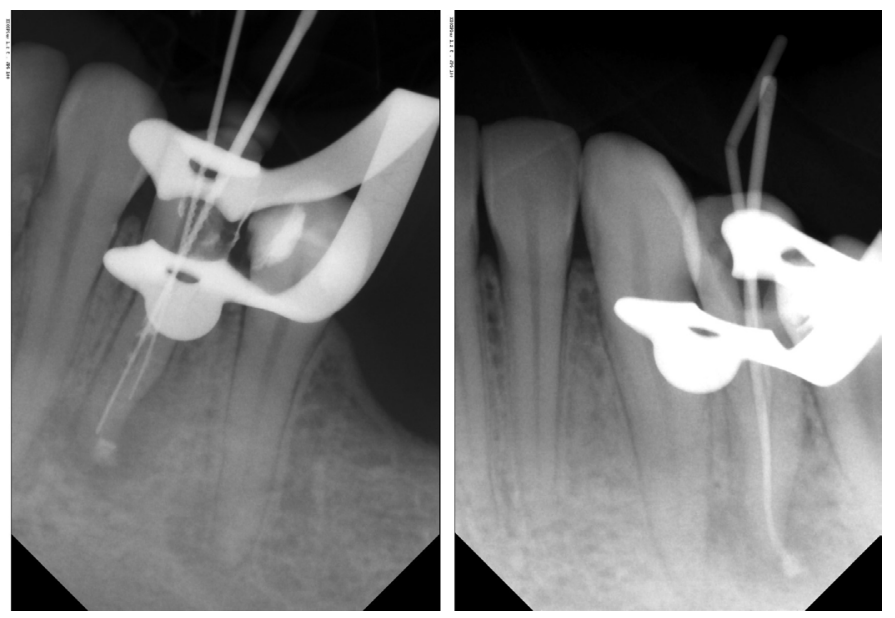

Figure 4: Master apical files radiograph. Figure 5: Master cone selection radiograph.

The canals were obturated with cold, lateral compaction of Gutta Percha cones (DENTSPLY) and a sealer AH-plus, Dentsplymellefer, Ballaigues (VD), Switzerland. The occlusal access opening was sealed with temporary felling material and a postobturation radiograph was taken to evaluate the quality of obturation. The two roots and canals of the first premolar can be appreciated well in this post-obturation radiograph (Figure 6).

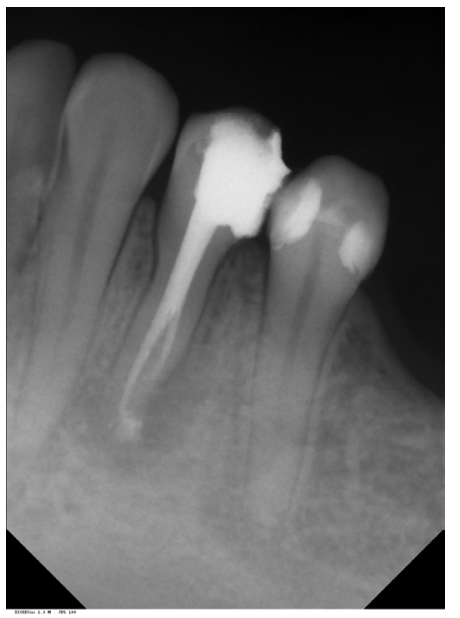

Figure 6: Post- operative radiograph with both canals obturated.

The patient was reviewed for three weeks and was referred to the department of prosthodontic for further management.

\section{Discussion}

When treating teeth endodontically, the anatomical variations, especially extra canals and roots, should be kept in mind.

The morphology of mandibular first premolar can be highly 
complex and extra canals can be found. Scott GR and Turner CG describe the accessory root of mandibular first premolar as tome's root. They reported the highest incidence of tome's root (more than 25\%) in Australian and sub Saharan African population. And higher incidence (44\%) in females compared to males (34\%) [2].

Slowey RR has shown that when the root canal shadow suddenly stops in the radicular region on radiograph, bifurcation or trifurcation of the canal at that point should be suspected. Also an additional root canal can be identified when the root outline is unclear or has an unusual contour, or deviates from the normal appearance on radiograph [3]. When the initial radiograph shows unusual anatomic root form, it is recommended to take a second radiograph from 15-20 degrees from mesial or distal horizontal angulation to accurately diagnose the number of roots and root canals [4].

Serman NJ and Hasselgren G in their radiographic survey reported that extra root and canal in mandibular premolar teeth is mostly situated bucco-lingually [5].

The use of magnification is necessary when locating and preparing such canals. One of the common reasons for having difficulty in identifying the second canal was inadequate access which leaves a shelf of dentine over the second canal [6]. The second canal usually leaves the main canal at a sharp angle nearly at a right angle. Slowey RR recommends the visualization of such canal configuration as a lower case letter ' $h$ ' where the main canal would be the straight line portion of the ' $h$ ' and the second canal exists about mid root at a sharp angle from the straight canal [7]. An adequate flaring of the coronal part of the canal is very important for straight line access of the instruments and for unobstructed passage of instrument into the second canal. Failure to recognize the presence of extra root canal will lead eventually to acute flareups during treatment and subsequent failure of endodontic therapy $[8,9]$.
Conclusion

A thorough knowledge of root canal anatomy and its variations, careful interpretation of the angled radiograph, close clinical inspection and tactile examination of the floor of the chamber and proper modification of access opening are essential for successful endodontic outcome.

\section{References}

1. Cleghorn BM, Christie WH, Dong CC. The root and root canal morphology of the human mandibular second premolar: a literature review. Journal of Endodontics. 2007; 33: 10311037.

2. Scott GR, Turner CG. Anthropology of modern human teeth. Cambridge University Press. 1997.

3. Slowey RR. Radiographic aids in the detection of extra root canals. Oral Surgery, Oral Medicine, Oral Pathology. 1974; 37: 762-72.

4. Fava LR, Dummer PM. Periapical radiographic techniques during endodontic diagnosis and treatment. International Endodontic Journal. 1997; 30: 250-261.

5. Serman NJ, Hasselgren G. The radiographic incidence of multiple rootsand canals in human mandibular premolars. Int Endod J. 1992; 25: 234-237.

6. Benjamin KA, Dowson J. Incidence of two root canals in human mandibular incisor teeth. Oral Surgery, Oral Medicine, Oral Pathology. 1974; 38: 122-126.

7. Slowey RR. Root canal anatomy. Road map to successful endodontics. Dental Clinics of North America. 1979; 23: 555573.

8. Habib AA, Kalaji MN. Root canal configurations of the first and second mandibular premolars in the population of north Syria. Journal of Taibah University Medical Sciences. 2015; 10: 391-395.

9. Glassman GD. Flare-up with associated paresthesia of a mandibular second premolar with three root canals. Oral Surgery, Oral Medicine, Oral Pathology. 1987; 64: 110-113. 